\title{
Ocean Temperatures in the Vicinity of Icebergs
}

\author{
Investigations Made for Promoting Safety at Sea
}

\author{
By C. W. Waidner, H. C. Dickinson, and J. J. Crowe
}

Throvar the courtesy of the Navy Department an opportunity was afforded to the represertatives of the Bureau of Standards to make observations on the temperature of sea water in the vicinity of icebergs and in the open sea with a view to obtaining information on the possibility of detecting the proximity of ice from temperature records. It is fairly evident from a long experience of navigating officers that the usual methods of taking the temperatures of sea water at widely separated intervals of time can give no useful information so far as detecting the proximity of icebergs is concerned. If any variations in the temperature are caused by the presence of ice, then continuous records of the temperature should be taken. The object of these experiments was to obtain such records and then to carefully analyze them with the view to ascertaining whether the proximity of icebergs gives rise to any definite temperature variations which can be distinguished from the accidental variations usually found in sea water.

The Bureau party embarked on the U. S. S. "Chester," leaving Philadelphia on June 2nd, 1912, under command of Capt. Decker. Mr. Crowe subsequently transferred to the U. S. S. "Birmingham," under command of Capt. Hughes, and continued observations from June 19th until the return to the port of Philadelphia on July 11th, 1912 TEMPERATURE EQUIPMENT.

The apparatus assembled for these experiments consisted of the following:

One electrical resistance thermometer with 50-foo leads, and one with 150-foot leads, protected and insulated by 4-ply rubber hose, the longer hose being reinforced with wire rope (the thermometers were of the Callendar compensated type with four flexible copper leads and coil of silk-covered nickel wire of about 100 ohms resistance); a surface electrical resistance thermometer, consisting of a flat coil of silk-covered nickel wire inclosed between copper sheets and insulated by thin layers of mica (the resistance of the nickel coil was about $100 \mathrm{ohms}$ ); deep-sea thermometers of the Negretti \& Zambra type, kindly loaned by the Bureau of Fisheries; several standard mercurial thermometers; a Leeds Northrup recorder suitable for use with the resistance thermometers, and which was kindly loaned for these experiments by the Leeds \& Northrup Company; a Siemens \& Halske Wheatstone bridge; a Leeds \& Northrup Wheatstone bridge with Kohbrausch slide wire; a Leeds \& Northrup marine D'Arsonval galvanometer; Siemens \& Halske high-resistance millivoltmeter; tools, wire, repair parts, etc.

All of the apparatus was carefully calibrated befor leaving the laboratory.

The surface thermometer was mounted with its fla face directly against the inner surface of the ship's $3 / 8$-inch plates, about 6 feet below the water line. The location of the thermometer was in the torpedo room, forward and on the starboard side. The thermometer was held into good contact with the plate by a suitable woode strut which was thermally insulated from the thermometer by a layer of felt, and the whole protected by a thick layer of cotton to eliminate the effects of the temperature of the torpedo room. Special experiments showed that this thermometer responded quickly to changes of temperature of the surface with which it was in contact. Simultaneous measurements of temperature made with a sensitive mercurial thermometer in the injection water and with the surface thermometer and recorder, mounted as above, showed that the sudden changes in sea-wate temperature were indicated by the recorder without any significant time lag. As an additional check on the calibration of the surface thermometer it was compared fre quently with standard mercurial thermometers.

The recorder was mounted on both ships in the torpedo room near the surface thermometer. The suspended system of the D'Arsonval galvanometer of this recorder was so carefully balanced by the makers that the records were entirely unaffected by the rolling and pitching of the ship, which was by no means inconsiderable, the rolling sometimes amounting to 20 degrees to 30 degrees on each sid of the vertical. As used, a change of 1 degree Cent. corresponded to a movement of the pen of 18 millimeters on the record sheet. The displacement of the paper was about 60 millimeters per hour. Full details of the operation of this recorder have been published in the curren engineering literature and may be had from the makers. This recorder, with the surface thermometer above de scribed, gave such excellent satisfaction that it was no

* Abstracts from Bulletin of the Buraau of Slandards, Vol. 10 No, 2.

necessary to use any of the other apparatus which was taken on the trip for emergency use.

\section{TEMPERATURE RECORDS.}

Practically continuous temperature records were obtained from June 4th until July 10th, 1912. The temperatures recorded ranged from $3 \mathrm{deg}$. to $25 \mathrm{deg}$. Cent. The balance point of the recorder was changed to bring the temperature records on the paper by the insertion of suitable known resistances in one arm of the Wheatston bridge circuit of the recorder, the calibration of the surface thermometer being made with the corresponding resistances in the circuit.

About 5.25 P. M. the ship lay-to abeam of a berg a a distance of 300 yards. A party put out in a small boat for temperature observations. The time until $7 \mathrm{P}$. M. was spent in the immediate neighborhood of the berg, the ship sailing around the berg while the party in the sma boat were taking observations. From about 7 to 9.30 P. M. the ship lay-to; by this time the ship and berg had drifted apart. During the remaining time, until about midnight, the ship cruised around in an unsuccessful effort to locate the berg with the aid of two powerful searchlights.

From measurements made with two stadimeters, o the ship and on the whaleboat, respectively, the dimensions of the berg were determined. The mass of ice in this berg was thus estimated at about 400,000 tons.

The mean of a number of temperature observations taken from the whaleboat gave the following surface temperatures: 20 feet from the berg, 4.5 degrees; 35 feet, 4.9 degrees; 50 feet, 5 degrees; 75 feet, 5.4 degrees 200 feet, $5.7 \mathrm{deg}$. Cent. The temperature at a distance of 50 feet from the berg and at a deptb of 5 fathoms wa 3.6 degrees, and at a depth of 20 fathoms 3.3 degrees. At some miles distant from the berg temperatures we encountered as low as those observed a few feet from the berg.

Although the effort to locate the berg with the aid of searchlights was unsuccessful, at daybreak on the morning of the 18th the berg was in plain view. Between 6 and 7 A. M. the berg turned over in an interval of about 10 minutes, accompanied by several loud reports similar to the reports caused by firing 3-inch guns.

On the morning of June 18th some time was spent in experiments to detect possible echoes, submarine and aerial, which are referred to elsewbere.

VARIATIONS IN THE SALINITY OF SEA WATE

Variation in the salinity of sea water in the neighborhood of icebergs due to the diluting action of the water resulting from the melting of the ice is so small as to be entirely masked by the accidental variations found in sea water. The following determinations of the densities of samples of sea water, taken under conditions specified and which were afterward tested in the laboratories, will serve to illustrate this:

\begin{tabular}{c|c|l}
\hline Sample. & $\begin{array}{c}\text { Specific Gravity } \\
\text { at } \frac{26^{\circ}}{4^{\circ}} \mathrm{C} .\end{array}$ & \multicolumn{1}{|c}{ Remarks. } \\
\hline 1 & 1.02339 & Close to berg \\
2 & 1.02352 & Close to another berg \\
3 & 1.02340 & 400 yards from berg \\
4 & 1.02336 & 40 miles from berg \\
5 & 1.02319 & 60 miles from berg \\
6 & 0.99923 & Water from berg ice \\
.7 & 0.99923 & Distilled water \\
\hline
\end{tabular}
ECHOES FROM ICEBERGS.

The testimony of numerous observers is in evidence that the echo of the foghorn may frequently, but by no means always, be detected when in the proximity of an iceberg or even of a bank of fog. The amount of evidence on this point leaves no doubt as to the correctness of the above statement. The experiment of sounding the foghorn when in the vicinity of a number of the bergs encountered on the trip was tried, but in no instance was an echo detected.

A fow experiments were also made to determine whether an echo could be detected under water coming Prom the larger submerged portion of the berg. For this purpose the ship's bell was lowered into the water and signals produced by striking the bell. Observers stationed at the ship's submarine signal telephones listened for evidences of the echo. The ship was at a distance of 1 to 2 miles from the fair-sized berg encountered by the U. S. S. "Chester" on the afternoon of June 17th. It was difficult to draw positive conclusions on account of the disturbing noises present in the telephone receiver, but a number of observers were convinced that they heard faint echoes. There was no time to investigate and improve the telephonic apparatus, so that the most that can be said is that these preliminary experiments looked hopeful enough to merit more careful experiments along these lines.

OTHER OBSERVATIONS.

The results of other experiments, such as firing 3 and 5 -inch shells into the berg, the utility of searchlights in locating bergs at night, etc., will undoubtedly be covered in the official reports of the commanding officers. It may be worth while to record, in passing, for the information of the reader, the general impressions of the authors, unfamiliar with such matters, that the effects of cannon fire in breaking up icebergs were disappointingly small and the utility of powerful searchlights in their location surprisingly limited.

Although the lookouts were provided with spyglasses or with binoculars, it is of interest to note that the icebergs were invariably first seen with the unaided eye. The difficulty of preking up icebergs under some conditions is illustrated by the following incident: While the ship was steaming toward a large berg in sight a heavy fog fell. There was one lookout in the crow's nest, four on the bridge, and two in the ship's eye. Notwitbstanding this the berg was first picked up from the quarterdeck after the ship had passed some 200 yards abeam.

Samples of ice broken trom the berg by gun fire were taken aboard ship. These contained considerable amounts of included air, which probably accounts for their white appearance. The ice was surprisingly hard and free from any definite cleavage planes. The whitish appearance was generally characteristic of all the bergs met with. In some instances there were narrow streaks of ice, transparent and of a blue color, that penetrated entirely through the bergs.

The water resulting from the melting of the berg ice was found to have the same density as that of distilled water. It was free from any characteristic taste.

So far as our observations go, the temperature of the air furnishes no evidence of value as to the proximity of a berg.

DISCUSSION OF OBSERVA'TIONS.

An examination of the temperature records, which were obtained under a variety of conditions in the region 37 degrees to 43 degrees 30 minutes nortb laditude and 43 degrees to 53 degrees west longitude, at once impresses one with the diffieulty of separating the large and sudden variations of sea water temperature, so frequently met with, from any variations that may be caused by the proximity of icebergs. The authors have obtained records in some parts of the ocean in which the temperatures were practically constant to a few tenths of a degree for many hours. On the other hand, some of the sample records show that the temperature variations in other parts of the ocean, where no ice is near, are as great and as sudden as any observed in the neighborhood of bergs. Having established the existence of such variations in sea water temperatures, it follows that it will be very difficult and often impossible to draw definite conclusions difficult and often impossible to draw definite conclusi In approaching or leaving a berg the temperature of the sea water may rise or fall or remain practically constant. Thus in approaching the large berg along our course the temperature varied irregularly through a range of about 0.2 deg. Cent., a variation much less than is frequently observed in this distance. Along some of the courses the temperature fell in approaching the berg and along one course the temperature varied quite irregularly.

The temperature records published by Prof. Barnes very generally show a rise in temperature as a berg is approached, occasionally accompanied by a slight fall in temperature very near the berg. Prof. Barnes regards the rise of temperature as the "characteristic loberg effect" and attributes any drop in temperature to oold currents. His records show the normal variations of water temperature in the localities of his observations to be very much smaller than were observed in the parts of the ocean where our observations were made. Although many of the small temperature variations which appear significant in his records would be completely masked by the large and sudden temperature changes which our records show, nevertheless the magnitude of the so-called "iceberg effect" observed by Prof. Barnes being often $0.5 \mathrm{deg}$. to $2 \mathrm{deg}$. Cent., such changes would be very evident on our records where changes of a few hundredths of a degree are readily discernible.

Our records do not corroborate Barnes's characteristic 
iceberg effect. Twelve of the fourteen curves obtained, as well as the mean curve, certainly show no such rise in temperature. Most of these curves indicate the opposite effect.

As Prof. Barnes's and our own records are matter of observation which unquestionably represent conditions that were actually encountered, it would seem that the effects due to bergs, if such effects can yet be regarded as established, must be different under different conditions. Indeed, that such is the case is shown by the different temperature records obtained in approaching a given berg along different courses.

Enough data is not yet at hand to formulate a theory to account for the variations of temperature observed in the vicinity of icebergs. Indeed, the question is still in doubt as to whether they influence to any measurable extent the temperatures of sea water at any considerable distance (a mile or so)

In view of the observations of Barnes and of the authors on the salinity of surface water at different distances from bergs, it seems fairly certain that the layer of cold, fresh water resulting from the melting of the berg, and which was supposed on Pettersson's theory to spread out over the surface in the vicinity of an iceberg, causes no measurable dilution or change of salinity of the surface layer.

Barnes's records so uniformly show a rise of temperature as the berg is approached that he has termed this chis effect is not characteristic "indeed, on the average, the authors observed a fall in temperature from a dis-
tance of several miles up to the bergs. In view of the tance of several miles up to the bergs. In view of the
erratic variations of the temperature of these parts of the ocean when no ice is near and of the fact that in approaching a given berg along different courses the temperature variations are quite different (being nearly constant over some courses and falling very appreciably over other courses), we would not deem it justifiable to conclude that the observed variations were certainly connected with the presence of the bergs.

It is interesting to inquire a little further into the question whether any cooling action of the berg could be expected to make itself felt at any considerable distance from the berg. If the berg is constantly drifting into new waters, such effect would obviously be impossible new waters, such effect would obviously be impossible from the consideration of the fact that it would require
the melting of about a million tons of ice to cool 1 square mile of the ocean to a depth of only 25 feet by $1 \mathrm{deg}$. Cent.; hence the possibility of any significant cooling action would require that the berg and the water in which it is immersed drift together for a considerable period of time, i. e., that the relative motion be small. This is probably true under some conditions, but by no means always. Considerations, such as these, of the enormous always. Considerations, such as these, of the enormous
mass of ice required to produce a cooling action distinguishable from temperature variations due to other causes, the slowness of melting of the berg, etc., render it doubtful whether any such effect could be distinguished with certainty at distances of a mile or so. To account for the observed rise in temperature or "iceberg effect" Barnes bas advanced an ingenious theory. He assumes that in regions of the ocean at some distance from the berg the surface layer, heated by solar radiation, is mixed with the colder water below by the "normal vertical circulation," while near the berg there is a current set up toward the berg due to the combined effects of the melting and cooling action of the berg. This current toward the berg, it is assumed, interferes with current toward the berg, it is assumed, interferes with remains on the surface. It is difficult to understand how a sufficiently strong current toward the berg could be set up by the melting and cooling action of the berg to interfere with the "normal vertical eirculation" at a distance of a mile or two. That there is no very strong current toward the berg seems to be indicated by the drifting apart of the fragments of a berg from the berg drifting apart of the fragments of a berg from the berg
itself or of the larger parts of a berg atter breaking up. Difference of wind action may, however, complicate any conelusions based on such observations.

\section{conCLUSIONS.}

The records of sea-water temperatures obtained by means of an electrical resistance thermometer and a Leeds \& Northrup temperature recorder, installed on the U. S. S. "Chester" and "Birmingham" in their patrol of the North Atlantic Ocean in June and July, 1912, show that the temperature variations in parts of the ocean far removed from ice are often as great and sudden as in the neighborhood of icebergs.

For a majority of the courses of the ship in the vicinity of icebergs there was a fall in temperature from a fraction of a degree to 3 degrees in a distance of 4 or 5 miles on approaching the berg. Records were obtained, however, in which the character of the temperature variation varied with the direction of approach to the berg, the temperature being nearly constant over one course, while over other courses the temperature rose or fell as the berg was approached. So far as our records go, therefore, it does not seem possible to draw positive conclusions as to the absence or proximity of ice from the temperature records of sea water. This is not a condemnation of the use of suitable recorders on ships. As Barnes has shown the temperature record may give valuable information on the approach to shore and shallow water, on the identification of characteristic ocean currents, and, as his records seem to show, even of the proximity of icebergs in some parts of the ocean where the variations are less erratic than in the regions in which our observations wer made.

If the "characteristic iceberg effect" observed by Barnes, i. e., rise of temperature on approaching iceberg had been present around the bergs observed by us and of the same or even much less magnitude, our records would have rendered such an effect evident, notwithstanding the irregular variations of temperature usually found to exist. In view of the differences in the character of the records obtained by Barnes and ourselves, it is very desirable that further observations be made in different part of the ocean, and under as varied conditions as possible, before attempting to draw final conclusions.

\section{Gelatine As a Food for the People*} By Ernst Homberger

Iт HAS been suggested in various places since the wa began that gelatine would prove an excellent substitute for meat. This is an extract of a nitrogenous substance composed of bones and calves' heads and feet. Exhibitions of gelatine foods have been held in Berlin, Frank furt-am-Main, Mannheim, Osnabrück, Stuttgart and other places.

It is certainly not by accident that the common peopl have of ten been kept alive by gelatine when other food stuffs were lacking. This is best proved by the fact that people turned to gelatine as a substitute for meat during the siege of Paris in 1870-71, that at several meetings of the Academy of. Science famous authorities declared themselves in favor of gelatine as food material, and that the French government seized all bones for food for the

The first one in Europe to be interested in gelatine wa Denys Papin, 1681, the celebrated inventor of the digestor. He conceived the idea of extracting gelatine from bones by boiling under strong pressure. He proposed to King Charles II of England to prepare 150 pounds of gelatine in twenty-four hours with the consumption of 11 pounds of coal. He wanted thus to solve the problem of turning three oxen into four. Some wags hung a touching petition about the necks of the king's doge, begging that the one thing that had been left to them by man should not now be taken away from them, and behold his Majesty was so touched that their right to bones was graciously left to them for the time being.

When after the French Revolution interest was taken in improving the food of the soldiers and poor people, and attention was again directed to gelatine, methods of producing gelatine were proposed by Proust, d'Arcet, Peletier, and Cadet de Vaux. At that time they judged the food value of a substance according to its content of nitrogen and its solubility; and gelatine was regarded as the only nutritious part of the meat and bone. It was thought that cheap gelatine would make a good substitute for meat and animal substances. The bones, according to this view, contained much more nutritious material than meat. Great worth was attached, therefore, to a glutinous bouillon of meat or bone.

By order of the Institute of France Guyton-Morveau and Deyeux, of the First Gelatine Commission, were required in 1802 to consider a report presented by Cadet de Vaux over the preparation of food from bone. The commission admitted that gelatine had nutritive qualities, that in certain cases it might even take the place of meat, but it did not regard it as established that the nutrition of any food could be

amount of gelatine it contained.

The Academy of Medicine of Paris had been asked in 1814 by the Société Philanthropique whether, and to what extent, gelatine was nutritious, and whether its use it as fully established that gelatine was a strengthening food, that it made meat broth nutritious and that it was the most nourishing of all animal matter. Thereupon its use became widespread in the public institutions of Paris and throughout France.

D'Arcet devoted thirty years of his life to getting gelatine used for a food for the people, actuated solely by the ideal of improving the lot of the poor and needy. Under his influence it was introduced into hospitals.

In Hotel St. Lazarre no less than two and three quarter million orders were served in the years 1829 to 1838. D'Arcet succumbed in a battle for a good cause. In the institution in which the soup was prepared according to his directions it was liked. But where it was carelessly prepared it was nauseating.

Scientific investigations such as were carried on by Donné failed because people did not know at that time *From Die Umschau.

xactly how questions of this sort should be decided.

This fault must also be laid at the door of the second commission which under Magendie experimented with gelatine on dogs. The chief fault of the commission was that it thought a substance refused by an animal because of its taste could not have food value, and further that it did not prescribe the quantity to be consumed by the animal. The commission observed insufficient nourishment; and this held not only with the rations of gelatine, but also when bread and meat were added. The commission set dry gelatine before the dogs, which they naturally refused to eat. Moreover, these creatures were kept in cages in a cellar. It was, therefore, no wonder that the experiments of the second gelatine commission were wholly negative in their results and that the commission ascribed no value to gelatine as a food product.

The previous exaggerations of the value of gelatine were now followed as the result of this opinion of Magendie by just as unjustified a reaction, in which no food value was ascribed at all to gelatine.

Frerichs, who was occupied in Germany with the same matter, objected to these experiments on the ground that the exact proportions of different food stuffs were not given, that the food given may not have contained the necessary organic and inorganic constituent parts, and that the animals failed because certain food stuffs were lacking and not because gelatine had no food value.

Mulder, too, refused to admit that Magendie's experiments were convincing, and says rightly: "In fact, the experiment which Magendie made with sugar proved that sugar has no food value. Everybody admitted this result and yet sugar is rightly classed among food stuffs." The same thing will be found to be true of gelatine.

Experiments had also to be made to find out how the white of an egg and a solution. of fat would behave under the influence of gelatine and whether gelatine would have any influence upon them at all.

It has been shown from the experiments of Bischoff and Voit that gelatine is dissolved as it goes through the cells with a nourishing fluid, and really dissolves more easily than albumen, which keeps it somewhat from solution. Gelatine saves albumen to a much greater extent than fat and carbobydrates; one hundred parts of gelatine taking the place of fifty parts of albumen. By greater proportions of gelatine, along with fat or carbohydrates, the loss of albumen in the body is much reduced; but it is never possible to safeguard the body from all loss of albumen; some nitrogen or albumen is always consumed. To the gelatine must always be added small quantity of albumen in order to maintain the proper amount in the body. Moreover, by supplying gelatine somewhat less fat is consumed.

According to Munk the importance of gelatine consists in this, that it is dissolved very quickly and completely in the cells and by its solution saves the albumen from solution. This quality of saving the albumen is an exceedingly important one and at least twice as great as that of carbobydrates and fats. One hundred grammes of dried gelatine take the place of 31 grammes of albumen (150 grammes of meat). Moreover, the consumption of fat is reduced by gelatine. Five-sixths of the albumen used can be replaced by gelatine. Accordingly gelatire represents a very valuable food product, which becomes of greatest importance where used for the economy of albumen.

It is, therefore, desirable that the value of gelatine a a food for the common people should be more and more recognized. If, besides gelatine, a certain amount of albumen is supplied to the body, and a certain amount of fats and carbohydrates to prevent the loss of fat, the normal condition of the body can be maintained. $\mathrm{Be}$ cause of its albumen-economy and fat-saving effects, and the ease with which it is digested, two men, Senator and Uffelmann, regard it as a valuable addition to fever diet. With the low appetite of sick people and the distaste for meat one can protect the body against loss of albumen by supplying gelatine.

The taste is improved by the addition of spices. Some sheets of gelatine put into a good soup is an easily digested and very nourishing dish. When at the siege of Paris the cannons were thundering outside the defenses, the Academy was occupying itself with questions of food. Dumas, who had been a member of the second gelatine commission, and Fremy, pointed to the extraordinary importance of gelatine as food, and to D'Arcet, in hi grave, justice was done for the great part he had played in introducing gelatine.

In like manner one should return during this world war to the idea of gelatine as material of the highent value for inexpensive food stuff for the masses.

\section{Gathering Food for Bees}

A Clever scheme, that appears to have originated in Scotland, is to gather pollen from flowers with a vacuum cleaner for use as food for bees. The heather on wide stretches of moors provides ample supplies, and it is said that in some places the young bees were mostly 